\title{
ZS Research Square \\ Relationship Between Patient-reported Orofacial-dental Pain Severity and Tele-triage Decisions During COVID-19 Pandemic - Does the Severity of Pain Drive Tele-triage Decisions?
}

Shaymaa Ali ( $\nabla$ shaymaabdulreda@gmail.com)

Hamad Medical Corporation https://orcid.org/0000-0003-3420-7096

Walid El Ansari

Hamad Medical Corporation

\section{Research Article}

Keywords: Orofacial pain, COVID-19, Teledentistry, Tele-triage, Dental emergencies. Pain Severity, COVID-19, Teledentistry, Tele-triage, Dental emergencies.

Posted Date: February 17th, 2022

DOl: https://doi.org/10.21203/rs.3.rs-1134460/v1

License: (9) (1) This work is licensed under a Creative Commons Attribution 4.0 International License. Read Full License 


\section{Abstract}

BACKGROUND: Globally, withCOVID-19 pandemic, elective dental services were stopped, and only urgent/ emergency conditions were managed face-to-face after tele-triage(TT). However, no previous researchexploredwhetherthe severity of orofacial/ dental pain (OFDP)drivesthe TT decisions. The current report undertook this task.

METHODS: This retrospective cross-sectional reportanalyzed the pain severity (PS) reported byhotline callers during the first COVID-19 lockdownand its association with patient's age,sex, history of chronic illness,and dental discipline required. PS was also compared across triage categories, associated dental history and tentative telediagnosis. PS was measured using self-reported numerical rating scale (NRS-11).Binomial logistic regression assessed the associationbetweenthe PS (exposure) and likelihoodof being referred for face to face management, controlling for age, sex, history of chronic illness, and dental discipline needed. ANOVA compared pain severity (PS) across dental history and tentative diagnosis.

RESULTS:PS was significantly associated with TT decisions $(\mathrm{p}<0.05)$. An increase in pain score by 1 unit was associated with 1.4 times increased odds of face-face referral. Pediatric/ adolescent patients (9-18 years) were 2.1 times more likely, and those with chronic illness were 2.12 times more likelyto be referred for face-tofacemanagement.Among the dental specialties, surgical and orthodontic specialties were each associated with increased odds of referral (1.9 and 7.016 respectively) compared to restorative specialties.

The highest PS was highest for the emergency triage category $(8.00 \pm 2.83, \mathrm{P}<0.0001)$, adults $(6.29 \pm 2.1819, \mathrm{P}<$ $0.0001)$, and the tentative tele-diagnosis of cellulitis $(7.75 \pm 2.872, \mathrm{P}<0.0001)$.

CONCLUSIONS: TT decisions were significantly influenced by severity of patient-reported OFDP, adjusting for a range of variables. However, acute dental conditions were not referred when they were judged to be manageable remotely; and conversely, less acute dental conditions were given the attention they required and referred when they hadpotential life threating or quality of life implications. Consideringsuch tele-approach after the pandemic has subsided might be safe and useful in a range of scenarios and healthcare facilities.

\section{Background}

As COVID-19 affected the world, it was soon categorized as a pandemic by the World Health Organization [1], and nationwide complete lockdown became the sole option [2]. This affected all aspects of health care including oral health. A complete move from the traditional care became critical, and virtual health technologies came to the forefront out of necessity to continue patient care and reduce risk of transmission [3]. In line with recommendations of the World Health Organization [4], Hamad Dental Center (HDC), the sole public tertiary dental services provider in Qatar, initiated changes related to all aspects of dental services. These included patient triage for COVID-19 symptoms, operatory preparation, infection control, and selection of low-risk interventions. HDC also initiated a dedicated teledentistry (TD) hotline to ensure the continuity of care to patients including triage, consultation, identifying oral diseases, and treating and/or rereferring according to the urgency of oral/dental condition [5]. TD applies to the remote provision of dental care without physical contact using broad variety of technologies [6], while tele-triage (TT) applies to using TD to interview callers, assess urgency and sort patients by priority and level of care required $[7,8]$. The aim was to maintain the continuity of services and avoid missing serious or emergency dental conditions. 
As part of the COVID-19 measures, the American Dental Association (ADA) published a guidance with definitions for different categories of dental conditions [6]. Dental pain was a fundamental component in these definitions as it is a highly prevalent and a significant health problem that reduces quality of life and well-being [9-12].

Pre-pandemic literature suggested that there is an elevated demand of emergency appointments in dental practices and in a certain proportion of general medical practices and emergency departments due to high level and frequency of orofacial/ dental pain (OFDP) [13]. Correspondingly, the pandemic literature suggests that the COVID-19 pandemic influenced the utilization of emergency dental services [14], and its impact on patterns of dental emergencies was shown in the high prevalence of dental pain compared to other oral health related problems during the pandemic [15 - 20]. It has also been suggested that during the pandemic, only patients with acute pain remained constant [21], while the less acute but nevertheless existing dental problems were neglected [22]. Such actions might have led to the worsening of overall health, triggering infections with local and systemic complications, compromising general health, and forcing at risk patients to visit hospitals emergency rooms [15, 23]. These complications were attributed to the use of the recommended advice, analgesics and antibiotics (AAA) strategy in dental pain management which has significant limitations with severe pain-related conditions where face-to-face dental procedures are necessary to achieve symptomatic relief [24].

While TD offers acceptable reliability for the tentative diagnosis [25], the literature on TT during the pandemic reveals knowledge gaps $[15,16,20,21,26]$. No previous research objectively reported whether TT decisions were driven by severity of pain. Likewise, according to our knowledge, no studies compared the pain severity (PS) across its associated symptoms, and tentative tele-diagnosis. Studies examined selective conditions e.g., dentalfacial trauma [27], or pain, swelling and trauma [15], with less attention to other conditions associated with OFDP e.g., loose/broken dental restorations, orthodontic appliances, oral ulcers, or bleeding. In addition, many reports focused on paediatric populations $[27,28]$ where PS cannot be objectively determined remotely.

Therefore, the aim of the current report is to assess whether tele-triage decisions were driven by severity of pain. PS was appraised across its associated dental history, and tentative tele-diagnosis to analyse their influence on tele-triage decisions. The emerging findings provide important information to a non-existent evidence base on the management of OFDP during pandemics. Findings will provide practitioners and policy makers with information necessary to better manage OFDP related emergencies during situations like those experienced during COVID-19 pandemic, or where resources are significantly limited for managing such emergencies.

\section{Methods}

\section{Ethics, Design and Participants}

The institutional research board (IRB) at Hamad Medical Corporation (HMC) granted permission for this service evaluation project to proceed. This is a retrospective analysis of information routinely collected for clinical audit and service evaluation. We analyzed patient, and triage data of all hotline calls during the first wave of Covid-19 lockdown ( $\mathrm{N}=1239$ for 5 months, 23 March - 31 August 2020). We excluded callers with incomplete records where outcomes were not reported $(n=389)$, and children $\leq 8$ years old $(n=125)$ as the numeric pain scale is not applicable to patients at this age $[29,30]$. We excluded patients who were not exposed to pain $(0$ pain score) $(n=$ 193). The inclusion of those with no pain could bias the results, as patients who did not report pain would be referred for face-to-face management for a reason other than the pain itself. 
After exclusions, the sample comprised 532 callers who reported various extents of pain. We. analyzed pain severity (PS) reported by callers and its association with patient's age, sex, history of chronic illness, and dental discipline required. We also assessed the association between the PS and likelihood of the TT decision of being referred for face to face management, controlling for the same variables. Data were extracted from the electronic health records and the TD data collection forms. The forms were completed by each tele-dentist for every caller, as part of an ongoing service audit.

\section{Setting and Procedures}

HDC set up a dental emergency services hotline managed by a team of qualified dentists to remotely consult, diagnose oral/ dental diseases, and undertake urgent TT decisions. TD policy and guidelines were formulated to guide the categorization of triage levels (emergency, urgent or non-urgent) and assist the team in the management of self-reported pain, swelling, bleeding, trauma, and oral-mucosal ulceration (Fig. 1). These guidelines were not binding but indicative, leaving some freedom of interpretation to the tele-dentists, who had been trained to ensure consistency of the service in arriving at triage and management decisions while observing caller privacy.

The recommended policy and guidelines, based on American and British recommendations [6, 31, 32], helped to triage the call, arrive at a tentative diagnosis, and accordingly offer appropriate care and/or referral. The guideline document was available to each practitioner and posted near the telephone set. In addition, as part of the service, dentists administered a TD data collection form (Fig. S1) for each call. The form collected information on: 1) call (frequency, time, duration); 2) patient (demographics, medical/ allergy history, relationship of caller to patient, chief complaint, severity of pain on scale from 0-10); and 3) triage (specialty required, management, referral to emergency/ dental facility undertaken, medications prescribed, procedure performed at point of referral). The focus of the current report is on the pain.

\section{Pain}

The numerical rating scale (NRS-11) is a simple and easy to score pain assessment tool [30] that consists of a total of 11 numbers, ranging from 0 to 10, representing no pain to the worst possible pain, respectively [33]. NRS11 is reliable and valid as a self-report scale of pain intensity in many populations including children and adolescents as young as 8 years old, however it is not suitable for very young children as certain cognitive skills are required for children to understand the meaning of the numbers of the NRS-11 and provide accurate ratings of PS [34]. Hence, callers $\leq 8$ years old were excluded.

Tele-dentists categorized the condition into emergency, urgent or non-urgent and managed the condition accordingly. AAA strategy was utilized as appropriate, and medications were home delivered to patients using courier service. Callers who were referred to hospital emergency or dental facility to receive face-to-face interventions were tele-triaged for COVID-19 symptoms and directed accordingly to either HDC or COVID-19 dedicated facilities.

\section{Statistical Analysis}

Descriptive and inferential statistics characterized the sample. Categorical variables are reported as frequencies and percentages and differences TT decisions compared using Fisher's Exact test (Monte Carlo test with 99\% Cl) due to relatively small sample size. Continuous variables are reported as mean \pm standard deviation and PS compared using t test if comparisons were between two groups or Analysis of variance (ANOVA) if > 2 groups. Binomial logistic regression assessed the association between the PS (exposure) and likelihood of being referred 
for face to face management, adjusted for age, sex, history of chronic illness, and dental discipline needed. Adjusted odds ratios are reported. Statistical analysis was performed using IBM SPSS Statistics for Windows, version 25 (IBM Corp., USA). $P<0.05$ (two-tailed) was considered statistically significant.

\section{Results}

\section{PS across selected sample characteristics}

Table 1 illustrates that majority of callers were adults (68.61\%), while there was almost equal proportions of males and females. About three quarters of the sample had no history of chronic illness. More than half of the callers needed restorative specialties that operate mainly aerosol generating procedures. The mean PS for the whole sample was moderate/ high $(6.05 \pm 2.284)$, with adults reporting significantly more severe pain than other age groups $(p<0.0001)$. Likewise, callers who needed restorative and surgical specialties reported moderate/ high PS, while those who needed orthodontic procedures demonstrated significantly less PS. PS did not differ by caller sex or history of chronic illness.

Table 1

Pain severity across selected characteristics of the sample

\begin{tabular}{|llll|}
\hline Characteristic & N (\%) & Pain Severity & P-value $^{\text {b }}$ \\
\hline Whole sample & $532(100)$ & $6.05 \pm 2.284$ & \\
\hline Age group & & & $<0.0001$ \\
\hline Child/ Adolescent 9-18 Y & $69(12.97)$ & $4.91 \pm 2.247$ & \\
\hline Adult 19-44 & $365(68.61)$ & $6.29 \pm 2.181$ & \\
\hline Middle Aged 45-64 & $60(11.28)$ & $5.93 \pm 2.350$ & \\
\hline Aged 65+ & $38(7.14)$ & $5.89 \pm 2.638$ & \\
\hline Gender & & & 0.330 \\
\hline Male & $252(47.4)$ & $6.15 \pm 2.193$ & \\
\hline Female & $280(52.6)$ & $5.95 \pm 2.363$ & \\
\hline History of chronic illness & & & \\
\hline No & $396(74.44)$ & $5.95 \pm 2.288$ & \\
\hline Yes & $136(25.56)$ & $6.32 \pm 2.260$ & \\
\hline Dental discipline required & & & \\
\hline Restorative Specialties & $312(58.65)$ & $6.24 \pm 2.239$ & \\
\hline Surgical Specialities & $150(28.2)$ & $6.23 \pm 2.190$ & \\
\hline Orthodontics & $70(13.16)$ & $4.79 \pm 2.315$ & \\
\hline
\end{tabular}

Pain severity (PS) represented as mean \pm standard deviation; restorative specialties = restorative dentistry, endodontics \& prosthodontics; surgical specialities = oral surgery \& periodontics; ${ }^{a}$ higher scores indicate higher 
severity of pain; ${ }^{b}$ P-value based on ANOVA test for comparison of means.

\section{Association between pain severity and tele-triage decisions}

The logistic regression analysis showed that an increase of 1 unit in pain score was significantly associated with 1.4 times increased odds of referral for face-to-face management. Three out of the remaining four variables included in the logistic regression were also significantly associated with tele-triage decision of referral for face-toface management (Table 2). The odds of face-to-face referral increased 2.1 times for patients of pediatric or adolescent age groups (9-18 years). Likewise, those with presence of chronic illness were 2.12 times more likely than those with no illness to be referred for face-to-face management. Among the dental specialties, surgical and orthodontic specialties were each associated with increased odds of referral of the patient for face-to-face management (1.9 and 7.016 respectively) compared to restorative specialties. Sex was not significantly associated with referral for face-to-face management.

Table 2

Association between reported PS and TT decision

\begin{tabular}{|lll|}
\hline \multicolumn{3}{|l|}{ Refer for face to face management } \\
\hline Variable & OR $(95 \% \mathrm{Cl})$ & P value \\
\hline Patient Age groups ${ }^{\mathrm{a}}$ (Years) & & \\
\hline Ref - adults (19-44) & & .061 \\
\hline Child/ adolescent (9-18) & $2.07(1.07-4.02)$ & .031 \\
\hline Middle aged (45-64) & $1.73(0.91-3.31)$ & .096 \\
\hline Aged (65+) & $0.86(0.36-2.05)$ & .737 \\
\hline Gender & & .960 \\
\hline Ref - female & $1.01(0.67-1.51)$ & .003 \\
\hline Presence of Chronic illness & & .000 \\
\hline Ref - Absence of illness & $2.12(1.28-3.51)$ & .000 \\
\hline Pain Scale (1-10) & $1.39(1.26-1.54)$ & .005 \\
\hline Dental Specialty Needed & & \\
\hline Ref - Restorative specialties ${ }^{b}$ & & \\
\hline Surgical Specialties ${ }^{c}$ & $1.93(1.22-3.04)$ & \\
\hline Orthodontics & & \\
\hline
\end{tabular}

$\mathrm{OR}=$ Adjusted odds ratios obtained for various factors using binomial regression; $\mathrm{Cl}=$ confidence interval; Ref = reference; ${ }^{a}$ age groups categorized as standard age ranges defined by the Medical Subject Headings (MeSH); ${ }^{b}$ restorative specialties $=$ restorative, endodontics and prosthodontics; ${ }^{\mathrm{c}}$ surgical specialties $=$ oral surgery and periodontics.

\section{Triage categories, TT decisions, and their relation to PS}


Table 3 displays that PS differed significantly across different triage categories with emergency category had highest PS $(P<0.0001)$. Likewise, TT decision significantly differed among different triage categories $(P<0.0001)$, were for all calls triaged as emergency, the TT decision was to refer for face-to-face management; $83.4 \%$ of calls triaged as urgent were referred; whilst only $2.9 \%$ of calls triaged as not urgent were referred. Although management decisions were based on the triage categories, however, when PS was tested against management decisions undertaken, there were also significant differences between them $(P<0.0001)$. Calls that were remotely managed were found to have a significantly lower PS $(5.69 \pm 2.227)$ than those where the management decision was to refer $(6.79 \pm 2.229)$.

Table 3

Triage categories, TT decisions, and their relation to pain severity

\begin{tabular}{|c|c|c|c|c|}
\hline \multirow[t]{7}{*}{ Triage categories } & & \multicolumn{2}{|l|}{ TT Decision ${ }^{b}$} & \multirow{3}{*}{$\begin{array}{l}\text { Total } \\
\mathbf{N}(\%)\end{array}$} \\
\hline & & Remote management & Referal & \\
\hline & & $N(\%)$ & $\mathrm{N}(\%)$ & \\
\hline & Emergency $(P S 8.00 \pm 2.83)^{a}$ & $0(0)$ & $4(100)$ & $4(100)$ \\
\hline & Urgent (PS7.13 \pm 2.05$)^{a}$ & $31(16.6)$ & $156(83.4)$ & $187(100)$ \\
\hline & Not urgent (PS5.43 \pm 2.17$)^{a}$ & $331(97.1)$ & $10(2.9)$ & $341(100)$ \\
\hline & Total & $362(68.07)$ & 170 (31.95) & $532(100)$ \\
\hline & Pain & $5.69 \pm 2.23$ & $6.79 \pm 2.23$ & \\
\hline
\end{tabular}

$P S$. pain severity on the numerical rating scale (NRS-11); all percentages represent row percentages; ${ }^{a}$ differences in PS across different triage categories and PS (ANOVA), P $<0.0001$; ${ }^{b}$ differences in TT decisions across triage categories (Fischer's exact test), $\mathrm{P}<0.0001$; differences in PS among different TT decisions (ANOVA), $\mathrm{P}<0.0001$

\section{PS differences across associated dental history, tentative diagnosis, and TT decisions}

In terms of dental history (Table 4), although tooth with cavity or filling were most frequent and most painful, only $21.78 \%$ were referred for face-to-face management. Similarly, jaw-related symptoms had the second highest PS, but only $40 \%$ of those callers were referred. Conversely, while orthodontic appliance problems had the lowest PS, $60 \%$ of these problems were referred for face-to-face clinical interventions.

As for tentative tele-diagnoses (Table 4), cellulitis was associated with the highest pain, and all cases were referred to a hospital emergency facility. Temporomandibular dysfunction (TMD) was also associated with high pain levels and $50 \%$ were referred for clinical management. Pulpitis was the most common tele-diagnosis (31.77\%) and was significantly associated with high PS, however, $76.33 \%$ were managed remotely. While orthodontic problems were associated with lowest pain levels, more than half of the callers could not be managed remotely and were referred for chairside interventions. 
Table 4

Pain severity differences across diverse dental histories, tentative diagnosis, and teletriage decisions.

\begin{tabular}{|c|c|c|c|c|c|c|}
\hline \multirow[t]{2}{*}{ Characteristic } & \multirow[t]{2}{*}{$\mathbf{N}(\%)$} & \multirow{2}{*}{$\begin{array}{l}\text { Pain } \\
\text { Severity }{ }^{a}\end{array}$} & \multirow{2}{*}{$\begin{array}{l}\text { P- } \\
\text { value* }\end{array}$} & \multicolumn{2}{|l|}{ Decision } & \multirow{2}{*}{$\begin{array}{l}\mathrm{P} \text { - } \\
\text { value**}\end{array}$} \\
\hline & & & & $\begin{array}{l}\text { Remote } \\
\text { Management }{ }^{b}\end{array}$ & Referal & \\
\hline Dental history & & & $<.0001$ & & & $\begin{array}{l}<.0001 \\
0.000\end{array}$ \\
\hline Tooth with cavity or filling & $\begin{array}{l}202 \\
(37.97)\end{array}$ & $\begin{array}{l}6.65 \pm \\
2.024\end{array}$ & & $158(78.22)$ & $\begin{array}{l}44 \\
(21.78)\end{array}$ & \\
\hline Jaw symptoms & $10(1.88)$ & $\begin{array}{l}6.60 \pm \\
2.547\end{array}$ & & $6(60.0)$ & $4(40.0)$ & \\
\hline Wisdom tooth & $43(8.08)$ & $\begin{array}{l}6.35 \pm \\
2.203\end{array}$ & & $33(76.74)$ & $\begin{array}{l}10 \\
(23.26)\end{array}$ & \\
\hline Swelling & $\begin{array}{l}86 \\
(16.17)\end{array}$ & $\begin{array}{l}6.17 \pm \\
2.181\end{array}$ & & $54(62.79)$ & $\begin{array}{l}32 \\
(37.21)\end{array}$ & \\
\hline Recent tooth extraction & $4(0.75)$ & $\begin{array}{l}5.75 \pm \\
3.403\end{array}$ & & $3(75.0)$ & $1(25.0)$ & \\
\hline $\begin{array}{l}\text { Dental restoration/ } \\
\text { prosthesis }\end{array}$ & $39(7.33)$ & $\begin{array}{l}5.74 \pm \\
2.673\end{array}$ & & $24(61.54)$ & $\begin{array}{l}15 \\
(38.46)\end{array}$ & \\
\hline $\begin{array}{l}\text { Dental trauma or tooth } \\
\text { fracture }\end{array}$ & $40(7.52)$ & $\begin{array}{l}5.70 \pm \\
2.115\end{array}$ & & $25(62.5)$ & $\begin{array}{l}16 \\
(37.5)\end{array}$ & \\
\hline Bleeding & $13(2.44)$ & $\begin{array}{l}5.23 \pm \\
2.315\end{array}$ & & $12(92.31)$ & $1(7.69)$ & \\
\hline Ulcer & $13(2.44)$ & $\begin{array}{l}5.23 \pm \\
2.455\end{array}$ & & $8(61.54)$ & $\begin{array}{l}5 \\
(38.46)\end{array}$ & \\
\hline Inflamed gums & $14(2.63)$ & $\begin{array}{l}5.07 \pm \\
1.940\end{array}$ & & $13(92.86)$ & $1(7.14)$ & \\
\hline Orthodontic appliance & $\begin{array}{l}68 \\
(12.78)\end{array}$ & $\begin{array}{l}4.71 \pm \\
2.350\end{array}$ & & $27(39.71)$ & $\begin{array}{l}41 \\
(60.29)\end{array}$ & \\
\hline Tentative diagnosis & & & $<.0001$ & & & $<.0001$ \\
\hline Cellulitis & $4(0.75)$ & $\begin{array}{l}7.75 \pm \\
2.872\end{array}$ & & $0(0.0)$ & $4(100)$ & \\
\hline TMD & $8(1.50)$ & $\begin{array}{l}6.75 \pm \\
2.375\end{array}$ & & $4(50.0)$ & $4(50.0)$ & \\
\hline Pulpitis & $\begin{array}{l}169 \\
(31.77)\end{array}$ & $\begin{array}{l}6.74 \pm \\
2.077\end{array}$ & & $129(76.33)$ & $\begin{array}{l}40 \\
(23.67)\end{array}$ & \\
\hline Dental caries & $52(9.77)$ & $\begin{array}{l}6.63 \pm \\
1.783\end{array}$ & & $40(76.92)$ & $\begin{array}{l}12 \\
(23.08)\end{array}$ & \\
\hline
\end{tabular}

${ }^{a} \mathrm{M} \pm \mathrm{SD}$, higher scores (1-10) indicate higher severity of pain, ${ }^{b}$ comprising AAA: advise, analgesics antibiotics; * $\mathrm{P}$ value based on ANOVA test for comparison of means; ${ }^{\star \star} \mathrm{P}$ value based on Fisher's Exact (Monte Carlo test with $99 \% \mathrm{CI}), \mathrm{TMD}=$ temporomandibular dysfunction. 


\begin{tabular}{|c|c|c|c|c|c|c|}
\hline \multirow[t]{2}{*}{ Characteristic } & \multirow[t]{2}{*}{$\mathrm{N}(\%)$} & \multirow{2}{*}{$\begin{array}{l}\text { Pain } \\
\text { Severity }{ }^{a}\end{array}$} & \multirow{2}{*}{$\begin{array}{l}\text { P- } \\
\text { value* }\end{array}$} & \multicolumn{2}{|l|}{ Decision } & \multirow{2}{*}{$\begin{array}{l}\text { P- } \\
\text { value** }\end{array}$} \\
\hline & & & & $\begin{array}{l}\text { Remote } \\
\text { Management } b\end{array}$ & Referal & \\
\hline Pericoronitis & $\begin{array}{l}57 \\
(10.71)\end{array}$ & $\begin{array}{l}6.25 \pm \\
2.214\end{array}$ & & 44 (77.19) & $\begin{array}{l}13 \\
(22.81)\end{array}$ & \\
\hline Dry socket & $5(0.94)$ & $\begin{array}{l}6.20 \pm \\
3.114\end{array}$ & & $3(60.0)$ & $2(40.0)$ & \\
\hline Dental abscess & $46(8.65)$ & $\begin{array}{l}6.11 \pm \\
2.046\end{array}$ & & 31 (67.39) & $\begin{array}{l}15 \\
(32.61)\end{array}$ & \\
\hline Dental fracture & 39 (7.33) & $\begin{array}{l}5.77 \pm \\
2.241\end{array}$ & & $23(58.97)$ & $\begin{array}{l}16 \\
(41.03)\end{array}$ & \\
\hline Saladenitis & $2(0.38)$ & $\begin{array}{l}5.50 \pm \\
2.121\end{array}$ & & $0(0.0)$ & $2(100)$ & \\
\hline $\begin{array}{l}\text { Broken dental filling/ } \\
\text { prosthesis }\end{array}$ & $32(6.02)$ & $\begin{array}{l}5.38 \pm \\
2.697\end{array}$ & & 19 (59.38) & $\begin{array}{l}13 \\
(40.62)\end{array}$ & \\
\hline Ulcer & $13(2.44)$ & $\begin{array}{l}5.23 \pm \\
2.455\end{array}$ & & $8(61.54)$ & $\begin{array}{l}5 \\
(38.46)\end{array}$ & \\
\hline Periodontitis & 35 (6.58) & $\begin{array}{l}4.97 \pm \\
2.051\end{array}$ & & 32 (91.42) & $3(8.58)$ & \\
\hline $\begin{array}{l}\text { Broken orthodontic } \\
\text { appliance }\end{array}$ & $\begin{array}{l}70 \\
(13.16)\end{array}$ & $\begin{array}{l}4.70 \pm \\
2.318\end{array}$ & & $29(41.43)$ & $\begin{array}{l}41 \\
(58.57)\end{array}$ & \\
\hline \multicolumn{7}{|c|}{ 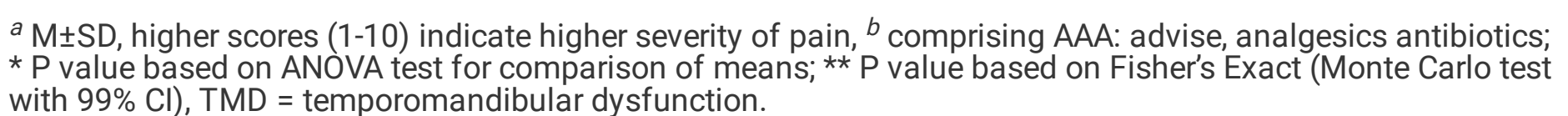 } \\
\hline
\end{tabular}

\section{Discussion}

There has been calls to enhance the evidence-base of the management of OFDP [35]. We assessed patientreported OFDP during the first wave of COVID-19 lockdown in terms of its differences in severity across demographic variables (age and gender), history of chronic illness, dental disciplines needed, dental history and tentative tele-diagnosis. The report's main objective was to explore whether TT decisions (remote management of caller vs referral for face-to-face management) were associated with the PS. To our knowledge, no previous research undertook such tasks. Hence, it was not straightforward to directly compare our findings with previous research.

The main finding was that TT decision to remotely manage or to refer the caller for face-to-face management was significantly associated with OFDP severity. An increase in pain score was associated with increased odds of faceface referral, however, other covariates were also associated with such decisions. Most significant associations were whether the caller had a history of a chronic illness, and whether the discipline needed operates aerosol generating procedures. This indicates that management decisions at HDC were highly individualized, considering the tripartite considerations of the reported pain, clinical judgement, and the high transmission characteristics of COVID-19. 
For instance, for callers with high PS, in terms of dental history, callers with problems related to tooth cavity/filling, temporo-mandibular joint, wisdom tooth, and swellings had the highest PS. However, more than two thirds of these patients were managed remotely. In terms of tele-diagnosis, we observed that pulpitis was not only associated with high PS, but it was also the most frequent tele-diagnosis (31.77\%), concurring with the range between $22.5 \%$ $46 \%$ pulpitis rates reported by others as the origin of OFDP during the pandemic $[15,18,19]$. Despite that endodontic RCT is the gold standard treatment for pulpitis, $>75 \%$ of our pulpitis were managed remotely, because RCT generates aerosols. Hence RCT was restricted during the pandemic and reserved for where the tooth was restorable and strategically important, otherwise extraction was favoured. This supports a UK study where $65 \%$ of clinical consultations resulted in extractions to avoid aerosol generating procedures [16]. This also explains the increased odds of the patients being seen at the clinic for surgical and orthodontic procedures (1.9 and 7.016 respectively) compared to that of aerosol generating restorative procedures.

Hight levels of pain severity were observed with conditions that could precede a serious medical emergency or are caused by odontogenic infections. Our management decisions considered the risk of systemic life-threatening complications in tandem with PS, as recommended by the ADA [6]. For instance, we observed that TMD was the second most painful condition. This supports that the pandemic adversely effected peoples' psycho-emotional status and intensified their bruxism and TMD symptoms [36]. However, during tele-triage, patients may provide inaccurate history [37] as TMD is difficult to be described by the patient. In addition, it could be an early symptom of an underlying cardiac problem [38]. Given such uncertainties combined with the fact that our TD was largely limited to telephone consultations during the pandemic's initial stages like other places worldwide [36], half of our TMD cases were referred. Likewise, although we found that cellulitis had the highest PS, pain was not the sole reason for referral. It is recognized that cellulitis of odontogenic infection origins can be life threatening [39]. All cellulitis were categorized by the HDC tele-dentists as emergency and referred to hospital emergency for intravenous antimicrobials and analgesics [39].

For callers with low PS, the individualized approach after careful weighting of reported pain and clinical picture was also evident. For instance, those with history of orthodontic appliance problems experienced least pain, but the majority were referred. The majority of orthodontic patients typically fall in the pediatric or adolescent group (918 years), and this could explain the 2.1 times increased odds of face-to-face referral for patients of this age group. Orthodontic appliance related problems may not be life threatening or severely painful; nevertheless, they challenge daily activities (speech, mastication, sleep), quality of life, and could lead to significant consequences if left unattended.

At the height of a rapidly changing pandemic, HDC management decisions provide positive lessons for future 'normal' times after the pandemic. On the one hand, during the pandemic, severe OFDP was the driver of urgent care [21]. On the other hand, pre-pandemic literature suggests that the high OFDP results in an elevated demand of emergency appointments at dental practices, some general medical practices and emergency departments [13]. The present report showed that PS indeed influenced the TT decisions of OFDP (remote management or referal). However, a main observation is that not all our cases with higher severity of pain were referred; and conversely, not all cases with low pain severity were managed remotely. Such discrepancies might seem odd. However, when dental history, tentative tele-diagnosis, discipline required and face-to-face procedure at point of referral were considered, other factors like clinical judgment, risk of disease transmission, potential life-threatening systemic complications, possible diagnostic uncertainty, and probable challenges with daily activities/ deteriorated quality of life if the condition is left unattended contribute to explain such discrepancies. The approach used at HDC 
during the pandemic led to the remote management of 31 cases triaged as urgent (5.8\% of the total callers) and 331 cases triaged as non-urgent (62.2\% of the total callers). During 'normal' (non-pandemic) times, these combined $68 \%$ of the patients would have otherwise physically presented themselves at our clinics. Hence, extending the application of teledentistry, tele-triage, tele-consultation, and tele-therapy to after the pandemic is over might offer a promising and useful approach if practiced with the same level of individualization and driven by considerations of both, the reported pain and clinical judgement. This would lead to the freeing of healthcare resources that could be used elsewhere, shortening of long waiting lists, alleviation of over-crowded walk-in clinics, and reserving the chairside appointments to conditions that truly require such management.

The current report has limitations. HDC is a tertiary dental services provider, and the patients in the current report are patients with previous dental experiences or persisting symptoms. Such patients are different than those who present at primary dental care centers experiencing their first dental pain encounter. Hence, generalizability of the findings needs to exercise caution. Despite this, the report has strengths. Previous work on patient-reported OFDP during the pandemic lockdown focused on the association between worsened socioeconomic conditions and pain severity [40], while the current report explored the influence of PS on TT decisions, and appraised PS across triage categories, demographic variables, dental history, discipline required, and tele-diagnosis related factors. These findings provide policy makers with information necessary to better manage OFDP related emergencies and similar epi/pandemics, or where resources are significantly limited in rural areas and underdeveloped regions.

\section{Conclusion}

During this phase of the pandemic, the most frequent symptom with most severe OFDP was decayed or filled tooth, and the most frequent tele-diagnosis was pulpitis. PS was significantly higher for emergency and urgent tele-triage categorization. TT decisions were significantly influenced by severity of patient-reported OFDP, adjusting for a range of variables. However, acute dental conditions were not inevitably referred when they were judged to be manageable remotely; and conversely, less acute dental conditions were given the attention they required and referred when they were judged to have potential life threating or quality of life implications. Such measured actions could lead to sizeable savings of healthcare resources which could in future be used to reduce pressure on clinics overcrowded with conditions that could be remotely managed. Hence, maintenance of such tele-approach later after the pandemic might be safe and useful for a range of scenarios and healthcare facilities if practiced with similar level of individualization and driven by careful considerations of the combination of reported pain and complaints on the one hand, and meticulous clinical judgement on the other.

\section{Abbreviations}

COVID-19: Coronavirus disease 2019; WHO: World Health Organization; CDC: Centers for Disease Control and Prevention; HDC: Hamad Dental Center, TD: Teledentistry; TT: Teletriage; ADA: American Dental Association; OFDP: Orofacial/ dental pain; PS: Pain Severity; AAA:advise, analgesics and antibiotics; IRB: Institutional research board; NRS-11: Numerical rating Scale; ANOVA: Analysis of variance; RCT: Root Canal Treatment;OR = Adjusted odds ratios obtained for various factors using binomial regression; $\mathrm{Cl}=$ confidence interval; Ref = reference.

\section{Declarations}

\section{Acknowledgements}

Page $11 / 16$ 
The authors thank the HDC call centre team for their wonderful work and for data collection which helped this report to come to light. We also thank Dr. N Srinivasan for his help with the statistical analysis and interpretation.

\section{Authors' contributions}

SA: Conceptualization, Data curation, Formal analysis, Investigation, Methodology, Project administration, Resources, Software, Supervision, Validation, Visualization, Writingoriginal draft, Writingreview and editing. WEA: Data curation, Formal analysis, Investigation, Methodology, Writingoriginal draft, Writingreview and editing. Both authors read and approved the final manuscript

\section{Declarations}

\section{Ethics approval and consent to participate}

The institutional research board (IRB) at Hamad Medical Corporation considered this analysis as an audit or service/therapy evaluation project since the data used was routinely collected for clinical audit and as an integral part of service evaluation purposes. The project was granted an exemption from requiring ethics approval.

\section{Consent to publish}

Not Applicable

\section{Competing interests}

The authors declare that they have no competing interests in relation to the present study.

\section{Funding}

This research did not receive any specific grant from funding agencies in the public, commercial, or not-for-profit sectors.

\section{Availability of data and materials}

The datasets generated and/or analysed during the current study are not publicly available due to the institution regulations, however, they are available from the corresponding author on reasonable request.

\section{References}

1. World Health Organization, Timeline of WHO's response to COVID-19.2020.

https://www.who.int/news/item/29-06-2020-covidtimeline. Accessed November 10, 2021.

2. Kshirsagar MM, Dodamani AS, Dodamani GA, Khobragade VR, Garg Y, Deokar RN. Teledentistry: A New Horizon in COVID-19 Pandemic for Oral Health. Int J Clin Pediatr Dent. 2021;14(3):441442. https://doi.org/10.5005/jp-journals-10005-1970

3. Kumar G, Rehman F, Al-Muzian L, Farsi D, Hiremath S. Global Scenario of Teledentistry during COVID-19 Pandemic: An Insight. Int J Clin Pediatr Dent. 2021;14(3):426-429.https://doi.org/10.5005/jp-journals-100051952 
4. World Health Organization (WHO). Consideration for the provision of essential oral health services in the context of COVID-19. Interim guidance. 2020. https://www.who.int/publications/i/item/who2019-nCoV-oralhealth-2020. Accessed Nov 19, 2021.

5. Hamad Medical Corporation. COVID-19 Hotline 16000. https://www.hamad.qa/EN/COVID19/Pages/default.aspx. Accessed November 10, 2021.

6. American Dental Association (ADA). What constitutes a dental emergency? 2020https://success.ada.org/ /media/CPS/Files/Open\%20Files/ADA_COVID19_Dental_Emergency_DDS.pdf. Accessed November 10, 2021.

7. Horton M, Harris R, Ireland R. 2001. The Development and Use of a Triage Protocol for Patients with Dental Problems Contacting an Out-of-hours General Medical Practitioner Cooperative. PDJ. 8(3):9397.https://doi.org/10.1308/135576101322561886

8. Huibers L, Smits M, Renaud V, Giesen P, Wensing M. 2011. Safety of telephone triage in out-of-hours care: A systematic review. Scand J Prim Health. 29(4):198-209.https://doi.org/10.3109/02813432.2011.629150

9. Locker D, Grushka M. The impact of dental and facial pain. J Dent Res. 1987;66(9):14141417.https://doi.org/10.1177/00220345870660090101

10. Lipton JA, Ship JA, Larach-Robinson D. Estimated prevalence and distribution of reported orofacial pain in the United States. J Am Dent Assoc. 1993;124(10):115-121.https://doi.org/10.14219/jada.archive.1993.0200

11. Macfarlane T, Blinkhorn A, Davies R, Ryan P, Worthington H, Macfarlane G. Orofacial pain: just another chronic pain? Results from a population-based survey. Pain. 2002;99(3):453-458.https://doi.org/10.1016/S03043959(02)00181-1

12. Santos P, Martins-Júnior P, Paiva S, Klein D, Torres F, Giacomin A et al. Prevalence of self-reported dental pain and associated factors among eight- to ten-year-old Brazilian schoolchildren. PLoS One. 2019;14(4):e0214990.https://doi.org/10.1371/journal.pone.0214990

13. Robertson D, Keys W, Rautemaa-Richardson R, Burns R, Smith A. Management of severe acute dental infections. BMJ. 2015;350(mar24 10):h1300-h1300.https://doi.org/10.1136/bmj.h1300

14. Guo H, Zhou Y, Liu X, Tan J. The impact of the COVID-19 epidemic on the utilization of emergency dental services. Journal of Dental Sciences. 2020;15(4):564-567.https://doi.org/10.1016/j.jds.2020.12.012

15. Beauquis J, Petit A, Michaux V, Sagué V, Henrard S, Leprince J. Dental Emergencies Management in COVID-19 Pandemic Peak: A Cohort Study. J Dent Res. 2021;100(4):352-

360.https://doi.org/10.1177/0022034521990314

16. Carter $E$, Currie $C$, Asuni $A$ et al. The first six weeks - setting up a UK urgent dental care centre during the COVID-19 pandemic. Br Dent J. 2020;228(11):842-848. https://doi.org/10.1038/s41415-020-1708-2

17. Eggmann F, Haschemi AA, Doukoudis D, Filippi A, Verna C, Walter C, Weiger R, Zitzmann NU, Bornstein MM. Impact of the COVID-19 pandemic on urgent dental care delivery in a Swiss university center for dental medicine. Clin Oral Investig. 2021;25(10):5711-5721.https://doi.org/10.1007/s00784-021-03872-1

18. Hahn B, Hollenberger L, Schlagenhauf U, Böhm H, Haubitz IR, Soliman S, Jockel-Schneider Y. The utilization of dental emergency services during COVID-19 pandemic in a German university center: Do we lose vulnerable patients? Quintessence Int. 2021;52(9):828-836.https://doi.org/10.3290/j.qi.b1702163

19. Kumar U, Gupta A, Goyal A, Gauba K. Impact of covid-19 pandemic on characteristics of dental emergencies and treatment services at tertiary care centre. Saudi Dent J. 2021;33(8):1018-

1023. https://doi.org/10.1016/j.sdentj.2021.06.004

Page 13/16 
20. Weintraub JA, Quinonez RB, Smith AJT, Ciarrocca K, Fouad AF, Shazib MA, Kraszeski MM, Rankin DB, Matthews NS. Responding to a pandemic: Development of the Carolina Dentistry Virtual Oral Health Care Helpline. J Am Dent Assoc. 2020;151(11):825-834. https://doi.org/10.1016/j.adaj.2020.08.003

21. Walter E, von Bronk L, Hickel R, Huth KC. Impact of COVID-19 on Dental Care during a National Lockdown: A Retrospective Observational Study. Int J Environ Res Public Health. 2021;18(15):7963. https://doi.org/10.3390/ijerph18157963

22. Romano F, Perotto S, Bianco L, Parducci F, Mariani GM, Aimetti M. Self-Perception of Periodontal Health and Associated Factors: A Cross-Sectional Population-Based Study. Int J Environ Res Public Health. 2020;17(8):2758.https://doi.org/10.3390/ijerph17082758

23. León S, Giacaman RA. COVID-19 and Inequities in Oral Health Care for Older People: An Opportunity for Emerging Paradigms. JDR Clin Trans Res. 2020;5(4):290-292. https://doi.org/10.1177/2380084420934742

24. Grossman S, Sandhu P, Sproat C, Patel V. Provision of dental services at a single institution in the UK's epicentre during the COVID-19 pandemic. Br Dent J. 2020;228(12):964-970.https://doi.org/10.1038/s41415020-1716-2

25. AlShaya MS, Assery MK, Pani SC. Reliability of mobile phone teledentistry in dental diagnosis and treatment planning in mixed dentition. J Telemed Telecare. 2020;26(1-2):45-52.

https://doi.org/10.1177/1357633x18793767

26. Sekundo C, Langowski E, Frese C. Influence of COVID-19 Restrictions on Patients' Self-reported Oral Health Care Needs. Oral Health Prev Dent. 2021;19(1):339-343. https://doi.org/10.3290/j.ohpd.b1693919

27. Ilyas N, Green A, Karia R, Sood S, Fan K. Demographics and management of paediatric dental-facial trauma in the 'lockdown' period: A UK perspective. Dent Traumatol. 2021;37(4):576-582. https://doi.org/10.1111/edt.12667

28. Wallace CK, Schofield CE, Burbridge LAL, O'Donnell KL. Role of teledentistry in paediatric dentistry. Br Dent J. 2021; 25: 1-6. https://doi.org/10.1038/s41415-021-3015-y

29. Flaherty SA. Pain measurement tools for clinical practice and research. AANA J. 1996;64(2):133-40. PMID: 9095685

30. Sirintawat N, Sawang K, Chaiyasamut T, Wongsirichat N. Pain measurement in oral and maxillofacial surgery. J Dent Anesth Pain Med. 2017;17(4):253-263.https://doi.org/10.17245/jdapm.2017.17.4.253

31. General Dental Council, UK. Preparedness For Primary Dental Care. https://www.gdc-uk.org/docs/defaultsource/covid-19/issue-2-prepardness-letter-for-primary-dental-care-20-march-2020.pdf?sfvrsn=69d46d90_2. Accessed November 10, 2021.

32. Centers for Disease Control and Prevention (CDC). Guidance for dental settings: interim infection prevention and control guidance for dental settings during the COVID-19 response. https:// cdc.gov/coronavirus/2019ncov/hcp/dental-settings.html. 2020. Accessed November 16, 2021

33. Downie WW, Leatham PA, Rhind VM, Wright V, Branco JA, Anderson JA. Studies with pain rating scales. Ann Rheum Dis. 1978;37(4):378-81.https://doi.org/10.1136/ard.37.4.378

34. Castarlenas E, Jensen MP, von Baeyer CL, Miró J. Psychometric Properties of the Numerical Rating Scale to Assess Self-Reported Pain Intensity in Children and Adolescents: A Systematic Review. Clin J Pain. 2017;33(4):376-383. https://doi.org/10.1097/ajp.0000000000000406

35. Scrivani SJ, Keith DA, Kulich RJ, DaSilva AF, Donoff RB, Handa S, Holland N, Lerman MA, McCauley JL, Reisner L, Resnick CM, Stohler CS, Vasciannie A, Fortino M, Schatman ME. Pain Management for Dental 
Medicine in 2021: Opioids, Coronavirus and Beyond. J Pain Res. 2021;14:1371-

1387. https://doi.org/10.2147/jpr.s319373

36. Emodi-Perlman A, Eli I, Smardz J, Uziel N, Wieckiewicz G, Gilon E, Grychowska N, Wieckiewicz M. Temporomandibular Disorders and Bruxism Outbreak as a Possible Factor of Orofacial Pain Worsening during the COVID-19 Pandemic-Concomitant Research in Two Countries. J Clin Med. 2020;9(10):3250. https://doi.org/10.3390/jcm9103250

37. Modgill O, Patel G, Akintola D, Obisesan O, Tagar H. AAA: a rock and a hard place. Br Dent J. 2021; 21:15.https://doi.org/10.1038/s41415-020-2594-3

38. Sharma A, Vidusha K, Suresh H, M J A, Saravanan K, Dhamania M, B N, Wani RT. Global Awareness of Myocardial Infarction Symptoms in General Population: a Systematic Review and Meta-Analysis. Korean Circ J. 2021. https://doi.org/10.4070/kcj.2021.0100

39. Opitz D, Camerer C, Camerer DM, Raguse JD, Menneking H, Hoffmeister B, Adolphs N. Incidence and management of severe odontogenic infections-a retrospective analysis from 2004 to 2011 . J Craniomaxillofac Surg. 2015;43(2):285-9.https://doi.org/10.1016/j.jcms.2014.12.002

40. Matsuyama Y, Aida J, Takeuchi K, Koyama S, Tabuchi T. Dental Pain and Worsened Socioeconomic Conditions Due to the COVID-19 Pandemic. J Dent Res. 2021;100(6):591-598.

https://doi.org/10.1177/00220345211005782

\section{Figures}




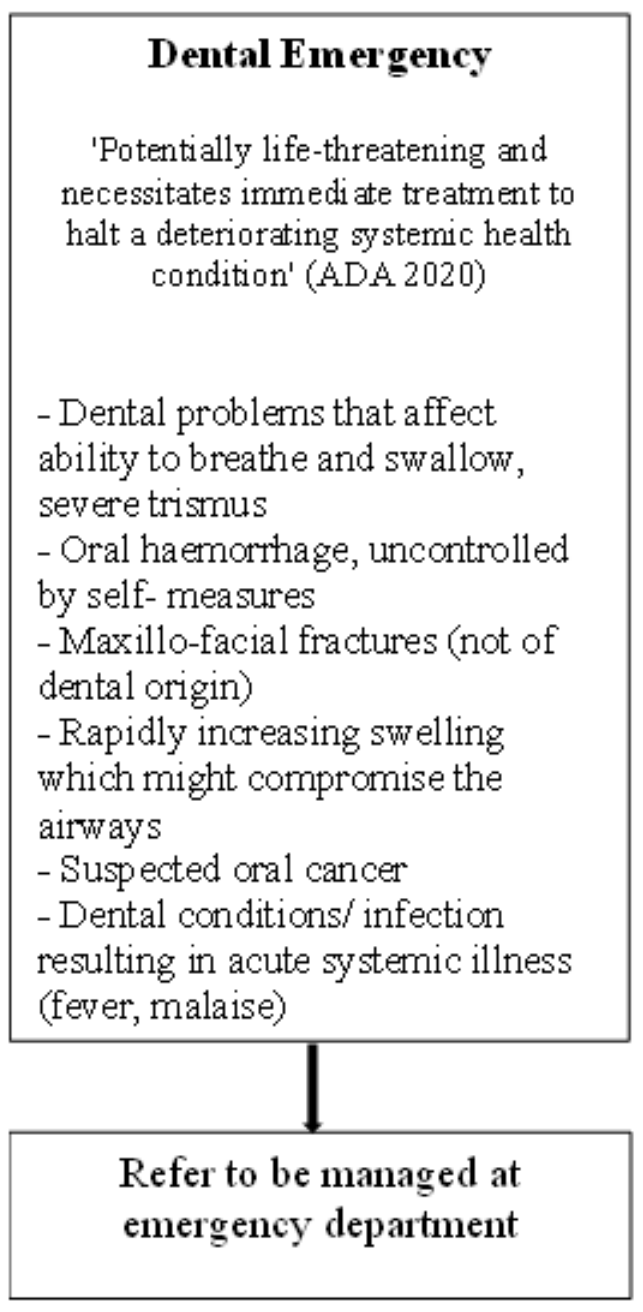

\section{Urgent Dental Condition}

'One that needs immediate attention to relieve severe pain and/or reduce the risk of infection'

(ADA 2020)

- Pain: severe, constant $>7$ on numeric pain scale, not responding to analgesics - Bleeding: post-extraction or post-surgical bleeding that cannot be self-controlled - Trauma: dento-alveolar trauma and oral tissue lacerations and/or injuries - Swelling: facial swelling without evidence of systemic involvement

\section{Non-Urgent Dental Condition}

'Requires measures such as aesthetic dental procedures' (ADA 2020)

- Others unlisted in emergency/ urgent care
Refer to be managed at facilities with urgent dental services

Figure 1. Recommend guidelines for self-reported dental emergencies via the hotline

\section{Figure 1}

See image above for figure legend.

\section{Supplementary Files}

This is a list of supplementary files associated with this preprint. Click to download.

- AdditionalFile1.docx 